\title{
In-group modulation of perceptual matching
}

\author{
Zargol Moradi • Jie Sui • Miles Hewstone • \\ Glyn W. Humphreys
}

Published online: 13 January 2015

(C) Psychonomic Society, Inc. 2015

\begin{abstract}
We report a novel effect of in-group bias on a task requiring simple perceptual matching of stimuli. Football fans were instructed to associate the badges of their favorite football team (in-group), a rival team (out-group), and neutral teams with simple geometric shapes. Responses to matching in-group stimuli were more efficient, and discriminability was enhanced, as compared to out-group stimuli (rival and neutral) - a result that occurred even when participants responded only to the (equally familiar) geometric shapes. Across individuals, the in-group bias on shape matching was correlated with measures of group satisfaction, and similar results were found when football fans performed the task, in the context of both the football ground and a laboratory setting. We also observed effects of in-group bias on the response criteria in some but not all of the experiments. In control studies, the advantage for in-group stimuli was not found in an independent sample of participants who were not football fans. This indicates that there was not an intrinsic advantage for the stimuli that were "in-group" for football fans. Also, performance did not differ for familiar versus unfamiliar stimuli without in-group associations. These findings indicate that group identification can affect simple shape matching.
\end{abstract}

Keywords Cognitive bias · In-group · Out-group · Football fans

\footnotetext{
Z. Moradi $(\triangle) \cdot J$. Sui $\cdot$ M. Hewstone $\cdot$ G. W. Humphreys

Department of Experimental Psychology, University of Oxford, South Parks Roadm, Oxford OX1 3UD, UK

e-mail: zahra.moradi@psy.ox.ac.uk

J. Sui

Department of Psychology, Tsinghua University, Beijing, China

G. W. Humphreys

Department of Speech and Language, University of Hong Kong, Hong Kong, China
}

Imagine standing in the front row of a stadium watching a match between your favorite and a rival football team. Suddenly the referee whistles to stop play, indicating that a player from your favorite team has handled the ball. You, on the other hand, are convinced that the ball struck the player's shoulder. Could this difference of opinion simply reflect a cognitive bias to favor your team, or could it reflect a difference in how you "see" the action, perhaps because you have "biased" perception of your player's actions? Does in-group identification affect basic perception?

Many accounts stress that perception is a bottom-up process, driven by the properties of stimuli computed in primary visual cortices and fed forward to subsequent recognition processes (e.g., Marr, 1982). However, there is considerable evidence for perceptual processes, and their associated neural substrates, being affected by top-down knowledge and expectations about stimuli (Chelazzi, Miller, Duncan, \& Desimone, 1993; Kastner \& Ungerleider, 2000), consistent with the view of perception as a predictive process (Spratling, 2008). Furthermore, perception in the real world does not occur in isolation, but in particular social contexts. The effects of stored knowledge on perception, then, may extend beyond cognitive factors to include effects of social context, and even factors such as group identification-for example, generating enhanced perception of stimuli associated with an in-group. This was investigated here in the context of a simple perceptual-matching task, with neutral stimuli that were associated with "in"- or "out"groups based on associations to rival football teams.

Much research has indicated that being a member of a group is commonly accompanied by categorizing the "self" and the "others" into in- and out-groups (Amodio, 2008; Tajfel, 1982). This group identification affects how strongly people empathize with others when they watch simple actions (Molenberghs, Halász, Mattingley, Vanman, \& Cunnington, 2012; Mathur, Harada, Lipke, \& Chiao, 2010), and it can 
modulate implicit association judgments (e.g., in the Implicit Associative Test [IAT]; Amodio, 2008; Greenwald, McGhee, \& Schwartz, 1998). It can also affect putatively perceptual tasks. For example, previous studies have suggested that group identification can modulate face processing. In the well-known "own-race effect," individuals show enhanced memory and identification for faces belonging to their own racial group, relative to faces belonging to other races (e.g., Brigham, Bennett, Meissner, \& Mitchell, 2007). The enhanced performance can be linked to the greater processing of the configural properties of own-race faces (e.g., based on the spatial relations between different facial features; Michel, Corneille, \& Rossion, 2007, 2009). The magnitude of this effect can vary with our experience with faces from other races, with the own-race bias reducing as experience increases with other-race faces (Brigham \& Malpass, 1985). However, there is also evidence that biases can be set up "on the fly," on the basis of in- and out-group coding. For example, configural coding is greater if other-race faces are categorized as belonging to the observer's own university group (Cassidy, Quinn, \& Humphreys, 2011; Hugenberg $\&$ Sacco, 2008). These data suggest that perception can undergo rapid modulation, depending on whether participants are motivated to classify individuals as in- or outgroup members.

Although there is evidence that group identification can affect perception, we still have little knowledge about the extent of such effects. Can such effects be found with stimuli that are much simpler than faces, and can they be established even for previously neutral stimuli that have newly formed associations with in- or out-group categories? Effects of social context on simple shape matching have recently been explored using novel associative-learning procedures. Sui, He, and Humphreys (2012) had participants associate neutral geometric shapes with a label relating either to themselves (e.g., "you"-circle), a friend ("friend"-square), or a stranger ("stranger"-triangle). Participants were then presented with shape-label pairs, with the task of deciding whether the pairs matched (e.g., you-circle, friendsquare) or mismatched (e.g., you-square, friend-circle). Responses to matching self-related stimuli were faster and showed higher perceptual sensitivity than did responses to other people. The data suggest that social categorization can moderate the perceptual processing of simple shapes.

In our research, we used the associative-learning procedure of Sui et al. (2012) to evaluate whether in-group identification affects matching performance for previously neutral shapes. Group identification was manipulated in a real-world context by testing football supporters. Rather than associating a geometric shape with a label (Sui et al., 2012), we had supporters associate a shape with the badge of the football club they supported or that of a rival team or of a neutral team without strong linkage to the favorite team. We asked whether matching of the shape linked to the badge of the favorite team would be enhanced, measured in terms of response time (RT), perceptual sensitivity ( $d$ prime), and response criterion. In addition, we went beyond prior studies on the self (Sui et al., 2012) by examining associative matching to a rival team. In this case, we asked whether matching might be poorer for such stimuli, when compared with neutral "baseline" associations, perhaps due to suppression of any association to a competing group.

We report five experiments. In Experiment 1, we used simultaneous badge-shape matching. For Experiment 2 we employed sequential matching, in which participants responded to the shape alone, after it had been preceded by the badge. Because participants respond directly to the shape in the sequential condition, advantages for in-group stimuli were then unlikely to be due to differences in the familiarity of the stimuli to which the response was initiated. These experiments were conducted in the field just before football matches took place, at a venue close to the home ground that was frequented by football supporters (a local hotel). Experiments $3 \mathrm{a}$ and $3 \mathrm{~b}$ replicated the results, but in this case the football supporters were brought into the laboratory to assess whether the biases observed in Experiments 1 and 2 were stable and did not depend on the heightened context of a match that was about to be played. For all of the experiments involving football fans (1-3), we also measured in-group identification on the basis of a multicomponent social-identity questionnaire (Leach et al., 2008). We hypothesized that in-group bias would be related to the degree of in-group identification of the individual participants, based on their satisfaction with being a member of the group. Experiments 4 and 5 were control studies. In Experiment 4, we recruited participants who were not football fans and who expressed no preferences for the badge of one football team over another. If the in-group advantage reflects intrinsic attributes of the in-group badge (e.g., its color and shape) that would facilitate its bottom-up processing across all participants, then the in-group bias should occur here, too. On the other hand, if an in-group advantage reflects group identification on the part of participants, then the advantage should only be found with supporters and not with nonsupporters. In Experiment 5, we tested whether variations in stimulus familiarity affect perceptual matching. Here we selected stimuli not linked to group membership but that varied more widely in their rated familiarity than the team badges used in the other experiments (we used images of animals that had been rated outside the experiment as being familiar or 
unfamiliar by an independent group of participants). If the in-group bias is related to the own-team badge simply being more familiar, an advantage should emerge in associative shape matching for familiar relative to unfamiliar animals. However, if group identification is critical, then participants should not show any preference for matching the familiar relative to the unfamiliar animals here.

\section{Experiment 1: simultaneous badge-shape matching}

\section{Method}

Participants Twenty-two football fans took part. Five participants were excluded due to having low levels of accuracy (accuracy rate $<.3$ in more than one condition). The participants were all male (mean age = 33 years \pm 10 ) who had been fans of the local professional football club (Oxford United) for at least 5 years. All were right-handed with normal or corrected-tonormal vision. The participants were recruited in the lounge of a hotel adjacent to the Oxford United football stadium $2 \mathrm{~h}$ before a match. Before running the experiment, a written consent form approved by the University of Oxford research ethics committee was completed by all participants.

Stimuli Four geometric shapes (circle, hexagon, square, and triangle) were presented, with each shape being paired with a badge for four different football teams. The teams were the participant's favorite football team (the in-group: Oxford United), the closest rival team (the out-group: Swindon Town), and two neutral teams (which participants neither liked nor disliked, Everton and Birmingham City). Participants were asked to associate each shape with one of the badges of the different clubs. The associations between the shapes and the badges were counterbalanced across participants. Each shape and badge $(160 \times 160$ pixels, corresponding to $4.5 \times 6.5 \mathrm{deg}$ of visual angle) was presented randomly approximately $4^{\circ}$ above or below the fixation cross $\left(1^{\circ} \times 1^{\circ}\right)$, at the center of the screen on a white background, and the stimuli were viewed from approximately $50 \mathrm{~cm}$. from the screen. The stimuli were displayed on a 14-in. monitor $(1,324 \times 768)$, and the experiment was run on a laptop using E-Prime software (Version 2.0).

Procedure In an initial block of 40 trials (ten for each badge-shape pair), participants were trained to associate the four shapes to (respectively) the badges of their own favorite team (Oxford United; yellow and blue badge), the local rival team (Swindon Town; red and white badge), and two neutral teams (Everton, Birmingham
City; both blue and white badges). After this, they performed a short practice block (20 trials) and then 240 experimental trials, half of which were "correct matches" (the badge and shape as originally paired), and half were mismatches (the badge and shape repaired). Each trial began with a fixation cross for $500 \mathrm{~ms}$, followed by a blank interval between 1,000 and 2,000 ms. A badge and shape were then presented simultaneously, one above and one below the fixation cross (randomly chosen) for $600 \mathrm{~ms}$. Participants judged whether the badge and shape were a pair as originally shown or whether they had been re-paired, with an RT limit of $1,500 \mathrm{~ms}$. Participants responded by pressing the $N$ and $M$ keys using their preferred hand. The key assignments for matching and mismatching trials were counterbalanced across participants. Feedback for each trial was given during practice but not on the actual test; however, the performance in the practice block was not included in the final analyses. Figure 1 shows a schematic representation of the task in Experiment 1.

Before the experiment, participants were asked to complete a "badge familiarity" survey. In this survey, participants rated the levels of familiarity of the badges of 16 different football clubs, including their favorite team and the traditional rival team, from 1 (not familiar) to 7 (perfectly familiar). Moreover, to measure explicit prejudice, participants also marked on a visual analogue scale how they felt about each of the 16 clubs, from 1 (like) to 7 (dislike) (for more details on the badges, please refer to the Appendix). To understand the extent of each fan's experienced link to their team, we adapted a multicomponent social identity questionnaire, which measures relatively stable levels of "belongingness" to relevant social categories (Leach et al., 2008). We also asked participants how many games per season they typically attended and which team they thought was the main rival to their own. For all experiments, the adequate sample size to produce a power of .80 was estimated in a pilot study. On the basis of the differences between the means of the conditions, a minimum sample size of 16 participants would yield power of .80 (see, e.g., Murphy, Myors, \& Wolach, 2009).

\section{Results}

All the participants classed Swindon Town as their rival team (for their team, Oxford United), and all classed Everton and Birmingham City as neutral teams. The mean familiarity ratings were: in-group $=6.88( \pm 0.33)$, rival $=6.64( \pm 0.42)$, neutral $1=5.82( \pm 0.39)$, neutral $2=5.64( \pm 0.49)$. These ratings differed across the teams, $F(3,48)=42.86, p<.0001, \eta^{2}=$ .728 ; this was due to the neutral teams being rated as less familiar than the rival, $t \mathrm{~s}(16)=6.42$ and 6.73 (respectively, for neutrals 1 and 2) and than the in-group, $t \mathrm{~s}(16)=10.18$ and $9.05, p \mathrm{~s}<.0001$, respectively. However, there were no differences between the two neutral teams, $t(16)=1.37, p<$ 


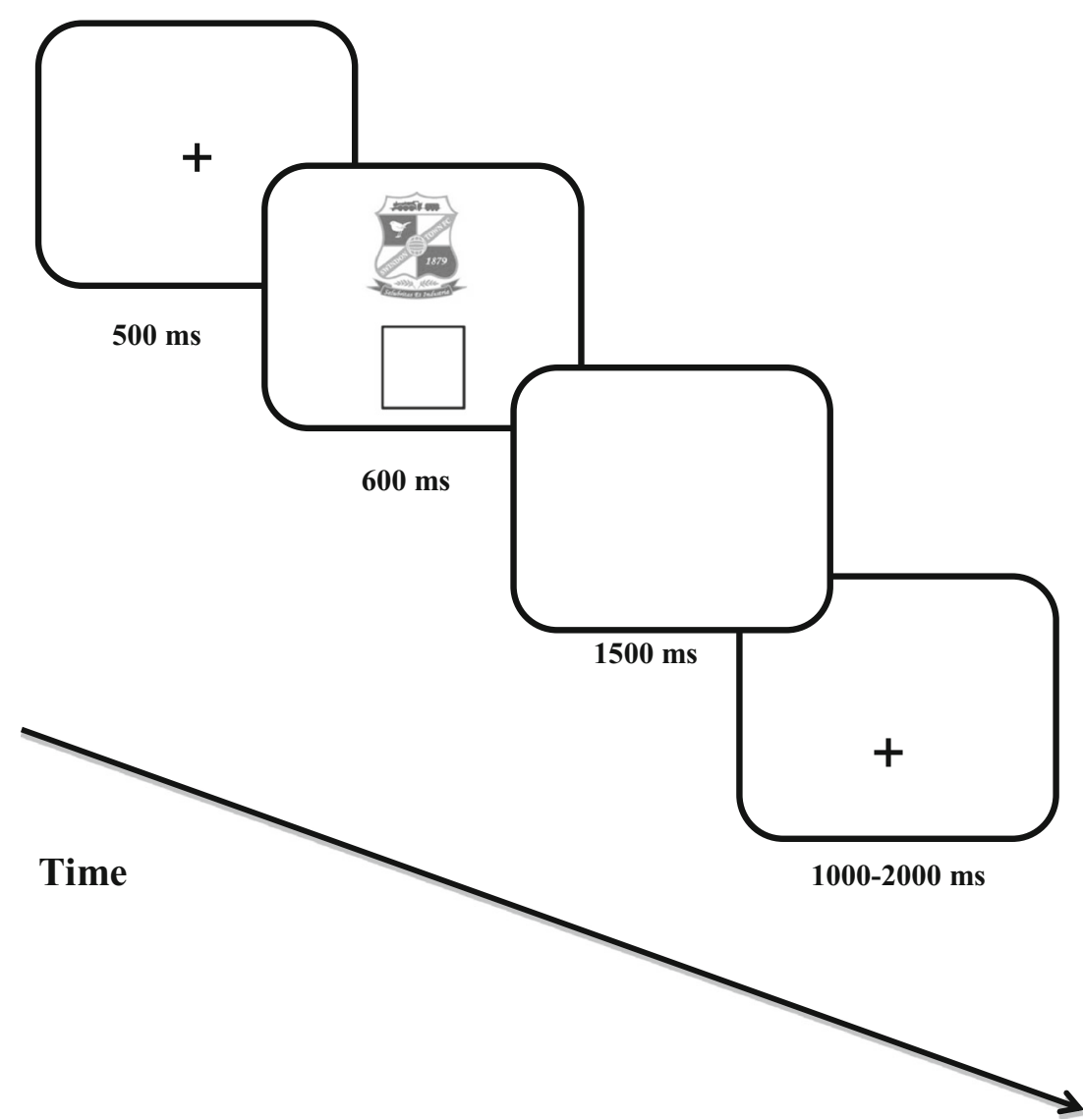

Fig. 1 Example task in Experiment 1 (simultaneous presentation). The original background was $50 \%$ gray, and the badge was red and white (representing Swindon Town football club).

.188 , or between the rival and in-group teams, $t(16)=$ $1.72, p<.188$.

The mean disliking ratings were: rival $=5.9( \pm 1.3)$, neutral $1=4.5( \pm 1.5)$, neutral $2=4.5( \pm 1.5)$. These ratings differed across the teams, $F(2,32)=49.70, p<.0001, \eta^{2}=.756$, with the rival team being rated as more disliked than the neutral teams, $t \mathrm{~s}(16)=7.1$ and 7.32, $p \mathrm{~s}<.0001$ (respectively, for neutrals 1 and 2), which did not differ, $t(16)=1, p<.332$. On average, participants attended 30 matches per year. The mean scores for the subcomponents of the in-group identification questionnaire were solidarity $=18.5( \pm 2.1, \max 21)$, satisfaction $=25( \pm 2.6, \max 28)$, centrality $=17.5( \pm 2.6$, $\max 21)$, in-group homogeneity $=10( \pm 2.7, \max 14)$, and self-stereotyping $=10( \pm 2.3$, $\max 14)$.

For each participant, correct responses shorter than $150 \mathrm{~ms}$ or longer than 1,000 $\mathrm{ms}$ (corresponding to approximately \pm 3 $S D$ s from the mean) were excluded. This resulted in rejecting $5 \%$ of the entire data set. The analysis was performed on the remaining trials.

For each participant, $d$ prime was calculated as a measure of sensitivity for discriminating match and mismatch trials across the different association categories. This measure was derived using the Green and Swets (1966) formula, by taking the data for mismatch trials, based on the badge that was presented:

$d^{\prime}=z(\mathrm{H})-z(\mathrm{~F})$.

In addition, the response criterion $(C)$ was calculated using the formula (Macmillan, 1993)

$C=-\S[z(\mathrm{H})+z(\mathrm{~F})]$.

$R T s$ We used $2 \times 3$ ANOVAs on the RTs with two withinsubjects variables, match condition (matched, mismatched) and team (in-group, rival, neutral 1, and neutral 2). Since the two neutral teams did not differ on measures of RT (means = 627 and $624 \mathrm{~ms}$.), $t(16)=1.74, p>.05$, the data were averaged across the two neutral teams. ${ }^{1}$

The analysis for the RT data showed a significant main effect of match, $F(1,16)=59.74, p<.000, \eta^{2}=.789$. Pairwise comparisons revealed that participants were in general faster on match trials than on mismatch trials, $p<.0001$. We found no significant main effect of team on RTs, $F(2,32)=2.43, p>$

\footnotetext{
${ }^{1}$ This procedure allowed us to maintain consistent analyses across the experiments, and subsequently to combine the data in an acrossexperiment analysis.
} 
$.05, \eta^{2}=.132$. However, the interaction between the match condition and the team was significant, $F(2,32)=12.02, p<$ $.0001, \eta^{2}=.429$.

To decompose the interaction, post-hoc comparisons were conducted separately on match and mismatch trials. On match trials, participants were quicker to respond to in-group stimuli than to stimuli linked to the rival team, $t(16)=2.74, p<.02$, and the neutral team, $t(16)=3.83, p<.001$. The rival and neutral teams did not differ, $t(16)=1.63, p<.12$. On mismatch trials, participants were significantly slower to respond to stimuli when either the in-group or the rival badge was present than when the neutral-team badge was present, $t(16)=3.29, p<.005$.

$D$ prime and criterion The $d$ prime scores did not differ between the two neutral teams (mean $=.66, .63), t(16)=1.77, p$ $>.05$, and therefore the data were averaged across the two neutral teams for the subsequent analyses. Analysis of the $d$ prime data revealed a significant main effect of team, $F(2,32)$ $=24.05, p<.0001, \eta^{2}=.600$. Pairwise comparisons showed that $d$ prime was larger for the in-group team than for other teams, $p \mathrm{~s}<.001$.

Analyses of the response criterion also revealed a significant main effect of team, $F(2,32)=34.18, p<.0001, \eta^{2}=$ .681. Pairwise comparisons showed that the criterion was significantly lower for the in-group than for the other teams, $p \mathrm{~s}<$ .001 , which did not differ significantly $(p \mathrm{~s}>.05)$.

The mean RTs on match and mismatch trials, along with the mean $d$ prime values for each team, are shown in Figs. 2a and $\mathrm{b}$.

The mean accuracy and RTs for the match and mismatch trials in Experiment 1 are presented in Table 1. The mean $d$ prime and criterion values in all experiments are presented in Table 2.

\section{Discussion}

The data indicated that there was a benefit on RTs and sensitivity ( $d$ prime) for matching the in-group badge with a shape, relative to conditions in which the rival-team or neutral-team badges were matched to a shape. This extended prior results in which shapes had to be matched with "self" or "other" labels (Sui et al., 2012), showing effects above the level of individual association. In addition to this, the rival team did not differ from the neutral teams. This last result suggests that the ingroup advantage was not tied to suppression of the rival group. In addition, we found evidence that a lower response criterion was adopted for the in-group than for the other teams. Given that $d$ prime and response criterion are independent (Macmillan, 1993), the data suggest that in-group association may affect more than one stage of processing - on the one hand, modulating perceptual processing (perceptual sensitivity), but on the other also affecting the response threshold, so that it is set lower to accept a match between the badge and a shape for the in-group than for the other teams. We will return to discuss this result after presenting the data from the other experiments.

\section{Experiment 2: sequential badge-shape matches}

Experiment 2 replicated Experiment 1, with two changes. The main change was that the badge preceded the shape to which participants responded, so that differences based on the familiarity of the stimulus that participants responded to should not modulate performance (participants never responded to the badge, but only to the associated shape). Secondly, we used one rather than two neutral stimuli. In Experiment 1, there had been few differences between the responses to the neutral teams; reducing the number of neutral teams made the association task easier to learn and reduced the numbers of trials, to make field testing easier.

\section{Method}

Unless differences are mentioned, the method was the same as in Experiment 1.

Participants Seventeen fans of the local professional football team (mean age $=35 \pm 9.5$ years) participated, all male. All other selection criteria were identical to those in Experiment 1.

Stimuli and procedure The stimulus and procedure were identical to Experiment 1, except that here we only included one neutral team (Everton), and the procedure on each trial involved first presenting the badge for $300 \mathrm{~ms}$ and then, at the offset of the badge, the shape (which matched or mismatched the badge) for $300 \mathrm{~ms}$. No participants had any difficulty identifying the badges at the presentation duration used. Responses were timed from the onset of the shape. Figure 3 shows a schematic representation of the task.

Results

The mean familiarity ratings were: in-group $=6.9( \pm 0.36)$, rival $=6.6( \pm 0.40)$, and neutral $=5.8( \pm 0.42)$. These ratings differed across the teams, $F(2,32)=37.02, p<.0001, \eta^{2}=.698$; this was due to the neutral team being rated as less familiar than the in-group, $t(16)=8.24$, and rival, $t(16)=5.89, p \mathrm{~s}<.0001$, teams. However the familiarity ratings did not differ for the in-group and rival stimuli, $t(16)=0.56, p<.58$.

The mean disliking ratings were: rival $=5.2( \pm 1.2)$ and neutral $=4.1( \pm 1.3)$. These ratings differed, $t(16)=3.95, p<$ .001 , with the rival team being rated as more disliked than the neutral team. On average, participants attended 32 matches per year. The mean score for the subcomponents of the in- 

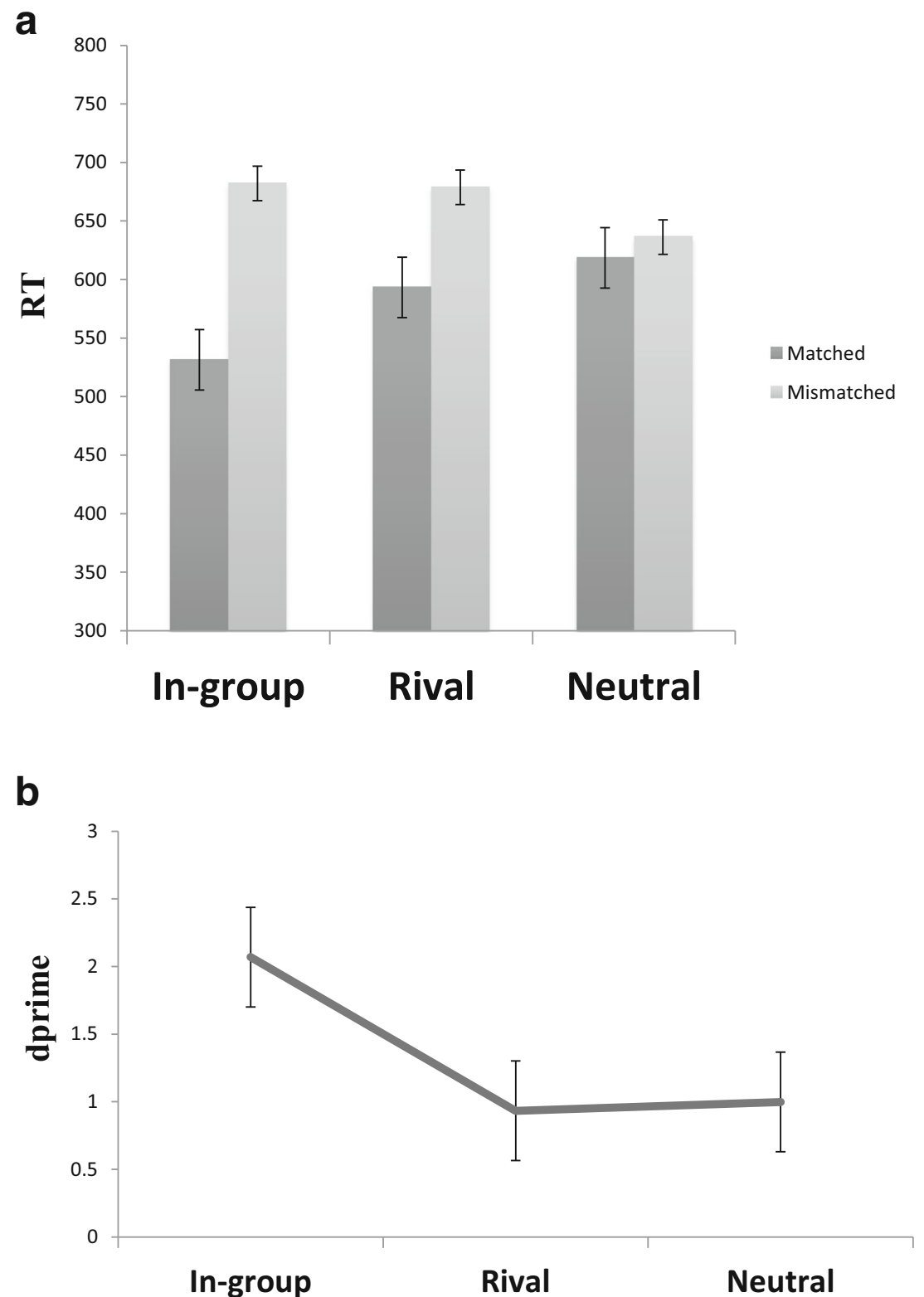

Fig. 2 (a) Mean correct RTs (in milliseconds) for match and mismatch trials (in milliseconds). (b) All $d$ prime values for each team in Experiment 1.

Table 1 Mean correct RTs (SDs in parentheses) and proportions of correct responses (SDs again in parentheses) in Experiment 1

\begin{tabular}{llll}
\hline Matching Condition & Group & RT & Accuracy \\
\hline Matched & In-group & $531(104)$ & $.91(.09)$ \\
& Rival & $593(120)$ & $.61(.15)$ \\
& Neutral 1 & $627(110)$ & $.61(.14)$ \\
& Neutral 2 & $624(111)$ & $.60(.12)$ \\
Mismatched & In-group & $682(119)$ & $.67(.13)$ \\
& Rival & $678(139)$ & $.71(.13)$ \\
& Neutral 1 & $636(121)$ & $.73(.16)$ \\
& Neutral 2 & $635(120)$ & $.72(.15)$ \\
\hline
\end{tabular}

group identification were: solidarity $=19( \pm 2.00, \max 21)$, satisfaction $=25( \pm 2.1, \max .28)$, centrality $=17.5( \pm 1.8$, max. 21), in-group homogeneity $=11( \pm 1.9$, $\max .14)$, and self-stereotyping $=11( \pm 2.1, \max .14)$.

$R T S$ For each participant, correct responses shorter than $150 \mathrm{~ms}$ or longer than $1,000 \mathrm{~ms}$ (corresponding to approximately $\pm 3 S D$ s from the mean) were excluded. This resulted in rejecting $2 \%$ of the entire data set. The analysis was performed on the remaining trials.

A $2 \times 3$ ANOVA was conducted on the RTs with two within-subjects variables, match condition (matched, mismatched) and team (in-group, rival, and neutral). We found a significant main effect of the 
Table 2 Mean $d$ prime and response criterion results for each experiment

\begin{tabular}{llcc}
\hline Experiment & Condition & $d$ prime & Criterion \\
\hline Exp. 1 (simultaneous) & In-group & 2.07 & -.54 \\
& Rival & 0.93 & .15 \\
& Neutral & 0.99 & .20 \\
Exp. 2 (sequential) & In-group & 2.23 & -.67 \\
& Rival & 1.17 & -.27 \\
& Neutral & 1.28 & -.56 \\
Exp. 3a (simultaneous) & In-group & 2.78 & -.41 \\
& Rival & 1.74 & .00 \\
& Neutral & 1.85 & -.13 \\
Exp. 3b (sequential) & In-group & 3.03 & -.27 \\
& Rival & 1.80 & .00 \\
& Neutral & 2.13 & .03 \\
Exp. 4 (control 1) & In-group & 3.00 & -.04 \\
& Rival & 2.80 & .01 \\
& Neutral & 3.13 & .06 \\
Exp. 5 (control 2) & Familiar (Cow) & 2.54 & -.04 \\
& Unfamiliar 1 (Donkey) & 2.27 & -.11 \\
& Unfamiliar 2 (Camel) & 2.27 & .09 \\
& Unfamiliar 3 (Zebra) & 2.39 & -.01 \\
\hline
\end{tabular}

match condition, $F(1,16)=19.71, p<.000, \eta^{2}=.552$ : Participants were significantly faster on match than on mismatch trials, $p<.000$. A significant main effect of team also emerged, $F(2,32)=24.27, p<.000, \eta^{2}=$ .603. Pairwise comparisons showed that participants were significantly faster for their in-group team than for both the rival and neutral teams, $p$ s $<.0001$. RTs to the rival and neutral teams did not differ. The interaction between match condition and team was not significant, $p>.05$.

$D$ prime and response criterion The analysis of the $d$ prime data showed a reliable main effect of team, $F(2,32)=$ 15.44, $p<.000, \eta^{2}=.491$. Pairwise comparisons showed that $d$ prime was significantly larger for the in-group team than for both the neutral and rival teams $(p s<.001)$, which did not differ. Analyses of the response criteria also showed a significant main effect of team, $F(2,32)=11.69, p<.001, \eta^{2}=.42$. Pairwise comparisons showed that the response criteria for both the in-group $(p<.001)$ and the neutral $(p<.006)$ teams differed significantly from that of rival team. The ingroup and neutral teams did not differ $(p>.05)$.

The mean RTs on matched and mismatched trials and $d$ prime values for each team in Experiment 2 are shown in Figs. $4 a$ and $b$.

The mean accuracy and RTs for the match and mismatch trials in Experiment 2 are presented in Table 3.

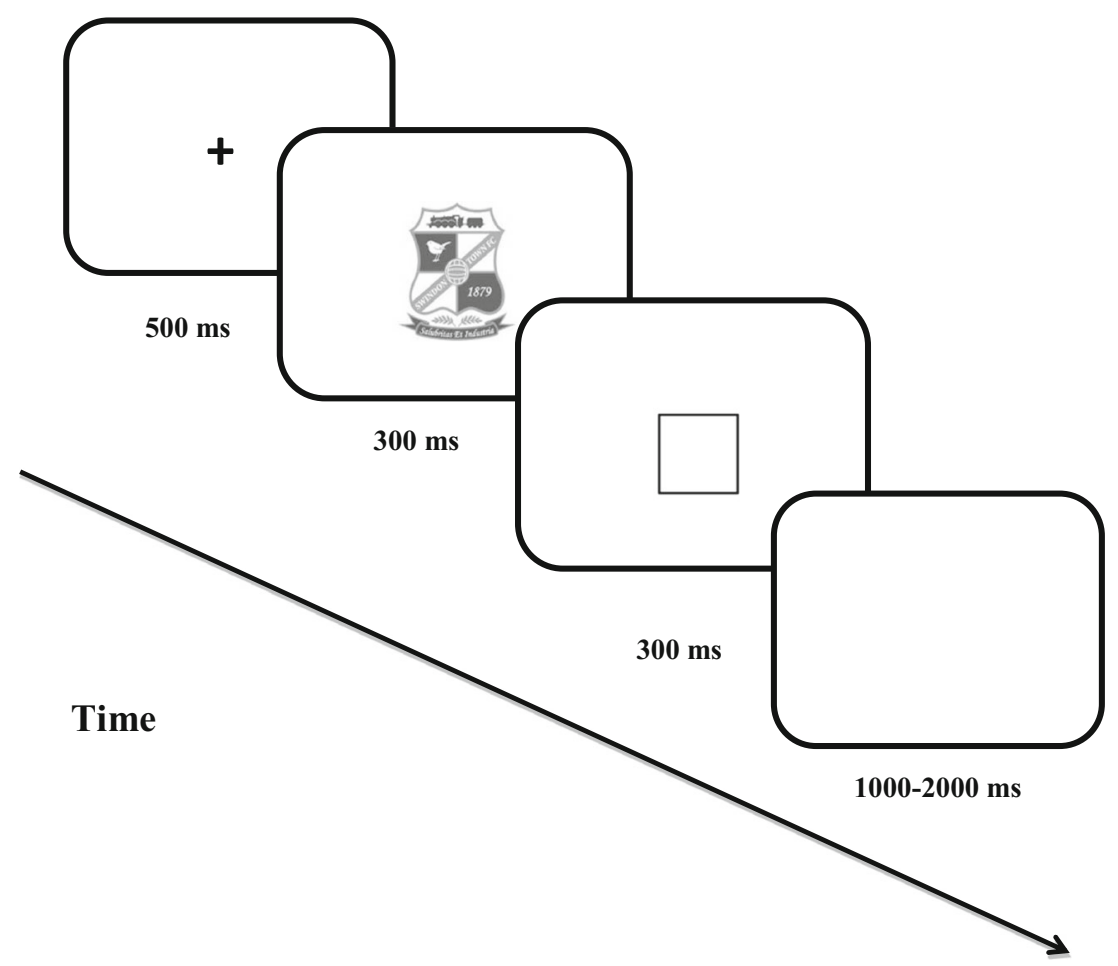

Fig. 3 Example trial in Experiment 2 (sequential presentation). The original background color was fifty percent grey and the badge was red and white (Swindon Town). 

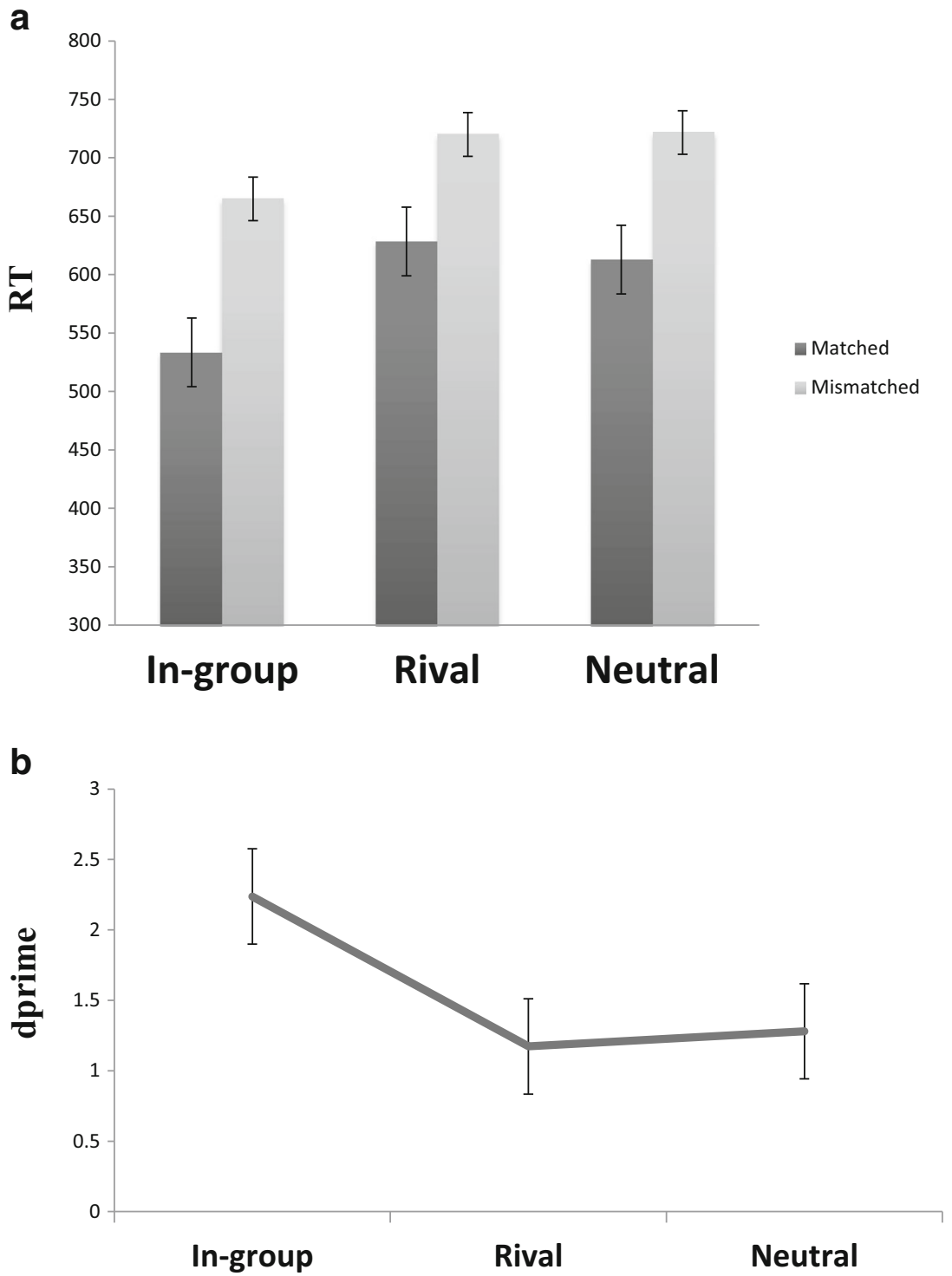

Fig. 4 (a) Mean RT (in milliseconds) for match and mismatch trials in Experiment 2 (sequential presentations). (b) All $d$ prime values for each team in Experiment 2.

\section{Discussion}

Experiment 2 replicated Experiment 1 and confirmed a benefit for matching in-group stimuli as compared to stimuli

Table 3 Mean correct RTs (SDs in parentheses) and proportions of correct responses ( $S D$ s in parentheses) in Experiment 2

\begin{tabular}{llll}
\hline Matching Condition & Group & RT & Accuracy \\
\hline Matched & In-group & $533(118)$ & $.95(.04)$ \\
& Rival & $628(117)$ & $.80(.06)$ \\
Neutral & $612(124)$ & $.85(.10)$ \\
& In-group & $664(99)$ & $.64(.16)$ \\
& Rival & $719(85)$ & $.60(.15)$ \\
& Neutral & $721(105)$ & $.52(.22)$ \\
\hline
\end{tabular}

associated with neutral and rival teams. This result occurred for both RTs and perceptual sensitivity, consistent with ingroup identification enhancing perception. As in Experiment 1 , we found no evidence for suppression of the rival team. The response criterion for accepting in-group matches was again set lower for the in-group than for the rival team, but in this case the in-group did not differ from the neutral team. This confirms that the $d$ prime effects are not linked to the response criteria, and that the in-group advantage (relative to the neutral team) does not necessarily stem from a shift in response bias, though there may be some bias when the in-group badge and shape are presented simultaneously (Exp. 1). On the other hand, the data do indicate that the response criterion can be conservative for the rival team. Interestingly, this had little impact on match RTs (which did not differ for the neutral and rival teams). 
One other change, under sequential as compared with simultaneous presentation conditions (in Exp. 2 vs. Exp. 1), was that the benefit for the in-group here was found on mismatching as well as on matching trials: When there is a positive response bias to the in-group stimuli (in Exp. 1, as compared with the neutral team), there may be a disruptive effect on mismatching responses involving the in-group badge. Here, no differential response bias was apparent for the in-group relative to the neutral stimuli, and responses to mismatching stimuli paired with the in-group badge were speeded rather than slowed. After Experiment 3, we will review how strongly these conclusions hold.

The results with sequential presentation are interesting, in that differences due to the familiarity of the badge should not modulate performance, since here participants never responded to the badge. This is also suggested by the pattern of the results. In both Experiments 1 and 2, the in-group and rival badges were rated as being more familiar than the neutral badges, though the in-group and rival ratings did not differ. In contrast, RTs in the in-group condition differed from those in the rival and neutral conditions. The data indicated that the results are unlikely to reflect some linear relation between stimulus familiarity and RT. In addition, the familiarity of the association between the badge and these shapes cannot be critical, since all of the associations were novel (between a badge and a neutral shape) and the shapes were counterbalanced across participants; any association would not be differentially familiar for the in-group than for the other teams. The familiarity of the association itself is not critical, but rather the association to the in-group, newly established, exerts a strong effect on matching performance. We examined this again in Experiment 5, in which rather than trying to eliminate the effects of familiarity (as here, by using sequential presentations), we manipulated effects of familiarity to test whether this factor alone can generate the bias effects that we observed.

\section{Experiments 3a and 3b: tests in a laboratory setting}

With Experiments $3 \mathrm{a}$ (simultaneous presentations) and $3 b$ (sequential presentations), we set out to replicate Experiments 1 and 2, but the data here were collected with football supporters in a laboratory setting rather than in the field. Can similar effects be established outside of the social context of the football ground and match, which might be expected to heighten in-group biases? The experiments were run within subjects to enable direct comparisons to be made between the different presentation modes (simultaneous vs. sequential).
Method

Stimuli and procedure For Experiment 3a, the stimuli and the procedure were identical to those of Experiment 1, except that we used only one neutral team. As in Experiment 1 , the badge and shape were presented simultaneously. For Experiment 3b, the stimuli and the procedure were identical to those of Experiment 2, and as before the badge and shape were presented sequentially. The same participants took part in Experiments $3 \mathrm{a}$ and $3 \mathrm{~b}$, and the order of presentation was counterbalanced between the participants, with a 1-h gap between the two experiments. The same badge-shape assignments were used in both experiments.

Participants Sixteen male fans of Oxford United (mean age $=$ $35 \pm 7$ years) took part.

Results

The mean familiarity ratings were: in-group $=6.6( \pm 0.50)$, rival $=6.3( \pm 0.34)$, and neutral $=5.9( \pm 0.33)$. These ratings differed across the teams, $F(2,30)=11.12, p<.0001, \eta^{2}=$ .426 , with the neutral team being rated as less familiar than the in-group, $t(15)=5.19, p<.0001$. However, the familiarity ratings did not differ for the in-group and rival teams, $t(15)$ $=2.07, p>.05$.

The mean disliking ratings were: rival $=5.7( \pm 1.3)$ and neutral $=3.8( \pm 1.2)$. These ratings differed across the teams, $t(15)=5, p<.0001$, with the rival team being rated as more disliked than the neutral team. On average, participants attended 21 matches per year. The mean score for the subcomponents of the in-group identification questionnaire were solidarity $=17.5( \pm 1.9$, $\max 21)$, satisfaction $=24( \pm 2.1, \max 28)$, centrality $=$ $16.7( \pm 2.2$, $\max 21)$, in-group homogeneity $=10( \pm 1.7$, $\max 14)$, and self-stereotyping $=10( \pm 1.5, \max 14)$.

$R T s$ For each participant, correct responses shorter than $150 \mathrm{~ms}$ or longer than $1,000 \mathrm{~ms}$ (corresponding to approximately $\pm 3 S D$ s from the mean) were excluded. This resulted in rejecting $2 \%$ of the entire data set. The analysis was performed on the remaining trials.

A $2 \times 3 \times 2$ ANOVA was conducted on the RTs, with three within-subjects variables: match condition (matched vs. mismatched), team (in-group, rival, and neutral), and viewing mode (simultaneous vs. sequential-Exp. 3a vs. Exp. 3b). We found a significant effect of match condition, $F(1,15)=37.92, p<.0001, \eta^{2}=$ .717: Across the two experiments, participants were significantly faster to respond to match than to mismatch trials $(p<.001)$. The effect of viewing mode was also significant, $F(1,15)=7.98, p<.013, \eta^{2}=.347$; in 
general, participants were faster in the sequential than in the simultaneous mode $(p<.05)$. This effect was not dependent on the order of the experiments, and did not interact with order when this was included as a factor. We observed a significant main effect of team, $F(2,30)$ $=36.62, p<.0001, \eta^{2}=.709$, and a reliable interaction between team and viewing mode, $F(2,30)=3.87, p<$ $.032, \eta^{2}=.205$. The interaction was decomposed using post-hoc comparisons for the sequential and simultaneous experiments. RTs to the in-group were faster than those to the neutral and rival groups, both when the stimuli were presented simultaneously $[t \mathrm{~s}(15)=4.60$ and $6.34, p s<.0001$, respectively] and when they were presented sequentially $[t(15)=3.80, p<.002$, and $t(15)$ $=4.9, p<.0001$, respectively]. The neutral and rival teams did not differ significantly, for either presentation mode. The interaction arose because the differences between the teams were larger when the stimuli were presented simultaneously, though the effects remained reliable under sequential presentation conditions.

$D$ prime and response criteria We also tested whether there were effects of viewing mode and team on $d$ prime. We found a main effect of viewing mode, $F(1$, $15)=5.18, p<.038, \eta^{2}=.257$; perceptual sensitivity was greater for sequential presentations (Exp. 3b) than for simultaneous presentations (Exp. 3a). A main effect of team was also apparent, $F(2,30)=110.62, p<$ $.0001, \eta^{2}=.871$. Pairwise comparisons showed that $d$ prime was larger for in-group stimuli than for both rival and neutral stimuli ( $p$ s $<.001)$. The $d$ prime scores for the rival and neutral teams did not differ significantly $(p>.09)$. The interaction between viewing mode and team was not significant. Thus, sensitivity was enhanced for in-group over the neutral and rival teams, and by the same magnitude for simultaneous and sequential presentations.

In the criterion data, the results showed a significant main effect of viewing mode, $F(1,15)=5.50, p<.033, \eta^{2}=.269$. The criterion was lower (i.e., participants adopted a less conservative criterion) in Experiment 3 a (simultaneous presentations) than in Experiment $3 b$ (sequential presentations). We also found a significant main effect of team, $F(2,30)=$ 25.15, $p<.0001, \eta^{2}=.626$. Pairwise comparisons showed that the response criterion for in-group stimuli was lower than those for both the rival and neutral teams, $p s<.0001$, which did not differ overall. However, the interaction between viewing mode and team was also significant, $F(2,30)=3.96, p<$ $.03, \eta^{2}=.209$ : The criterion for in-group stimuli was lower than those for both the rival and neutral teams, with both simultaneous $[t \mathrm{~s}(15)=7.6$ and $4.47, p \mathrm{~s}<.0001$, for in-group vs. the rival and neutral teams] and sequential $[t(15)=7.28, p<.0001$, and $t(15)=3.92, p<.001$, for in-group vs. the rival and neutral teams] presentations. However, the criteria for neutral and rival teams did not differ in either the sequential or the simultaneous presentation condition (see Table 2).

To examine the relations between the effects of team on the criterion and $d$ prime, we correlated the two measures across the experiments. No significant correlations emerged for the in-group $(r=.074, n=66, p<$ $.57)$, rival $(r=.149, n=66, p<.235)$, or neutral $(r=$ $.147, n=66, p<.244)$ team. $^{2}$ We also conducted correlation analyses on RTs and accuracy, to ensure that the data did not stem from any speed-accuracy tradeoffs. Again, no correlations emerged for the in-group ( $r$ $=.10, n=66, p<.43)$, the rival $(r=-.051, n=66, p$ $<.68)$, or the neutral $(r=.074, n=66, p<.57)$ team. $^{3}$

The mean RTs on match and mismatch trials and the $d$ prime values for each team in Experiment 3a (simultaneous presentation) are shown in Figs. 5a and $b$. Figures $6 \mathrm{a}$ and $\mathrm{b}$ show similar data for Experiment $3 \mathrm{~b}$ (sequential presentation).

The mean accuracy and RTs for the matched and mismatch trials in Experiment 3 a are presented in Table 4. Table 5 presents similar data for Experiment $3 b$.

Questionnaire analysis Our results indicated that across four experiments, performance was enhanced for ingroup matches relative to matches to a neutral stimulus. We next investigated how this enhanced performance for the in-group related to scores on the subcomponents of the in-group identification questionnaire. In order to utilize both RTs and accuracy within a single measure, we calculated inverse efficiency (IE) as a single score reflecting both accuracy and RT, by dividing RTs by proportion-correct response rates separately for each condition (higher values indicate worse performance; Röder, Kusmierek, Spence, \& Schicke, 2007; Townsend \& Ashby, 1983). This measure was calculated only for match trials. The difference between the IE scores for each participant's own team and the rival team was then used as a measure of "in-group bias." "We tested whether indices of in-group bias in the matching task were associated with the solidarity, satisfaction, and centrality subcomponents of the in-group identification questionnaire. We combined the data across Experiments 1 and 3a (simultaneous presentations) and Experiments 2 and $3 \mathrm{~b}$ (sequential presentations) in order to maximize

\footnotetext{
${ }^{2}$ Note that the total number of "participants" was 66 , reflecting the separate sessions for Experiments $3 \mathrm{a}$ and $3 \mathrm{~b}$.

${ }^{3}$ This correlation analysis was conducted for matched trials across Experiments $1,2,3 \mathrm{a}$, and $3 \mathrm{~b}$.

${ }^{4}$ The contrast was made between the in-group and rival teams, here in order to maximize the in-group bias effect while equating the stimuli for familiarity (which was matched for the in-group and rival teams).
} 
power. For both sets of experiments, we found a positive correlation between ratings of a participant's satisfaction with the in-group team and the matching advantage for the in-group team as compared with the rival team: $r=.653, n=33, p<.0001$, for Experiments 1 and $3 \mathrm{a} ; r=.497, n=33, p<.003$, for Experiments 2 and $3 \mathrm{~b}$. The scatterplots are presented in Figs. $7 \mathrm{a}$ and $\mathrm{b}$ (for simultaneous and sequential presentations, respectively).

We observed no significant correlations between other subcomponents of the in-group identification questionnaire and in-group bias on the matching task. There were also no correlations between the in-group bias and the rated familiarity, number of matches attended, and reported disliking rate for the local rival team.

\section{Discussion}

The laboratory data (Exps. 3a and 3b) replicated the results collected in the field (Exps. 1 and 2). The data indicate the stability of the results across different experimental contexts and that the in-group advantage is not dependent upon the heightened environment of participants being tested in close temporal proximity to an in-group football match.

As in the earlier experiments, some differences were apparent between the effects with simultaneous and sequential presentations. The in-group advantage was larger for simultaneous than for sequential presentations, and the response criterion tended to be less conservative for simultaneous exposures. The reduced advantage for sequential presentations can be attributed to the visual complexity of the target displays being reduced (i.e., a shape was presented alone under sequential presentation conditions, as opposed to the badge and shape appearing together) and to participants being able to use top-down prediction under sequential conditions. Nevertheless, the in-group effects were robust across the conditions and were present on $d$ prime, and not just on the response criterion. Unlike in Experiment 1, however, the in-group advantage was present in both match and mismatch trials (similar to Exp. 2). The data suggest that under the conditions of heightened group awareness immediately prior to a football match (in Exp. 1, but not here), mismatch trials linked to both the in-group and rival-team badges were slowed, perhaps reflecting the involvement of some further factor, such as arousal. This speculation needs to be tested in future experiments.

Combining the data across experiments, we found that the in-group bias correlated with measures of group satisfaction, and this was replicated across both the simultaneous and sequential presentation conditions. This provides converging evidence that ingroup identification is critical to producing our results. This was tested in Experiment 4, in which we used the same stimuli as here, but with individuals who were not football supporters, to assess whether the effects depended on the stimuli themselves (e.g., the color of the Oxford United vs. the Swindon Town badge) or on the individual's association with the ingroup team.

\section{Experiment 4: effects with nonfootball fans (control study 1)}

Experiment 4 was a control study undertaken with participants who were not football fans in order to assess whether the in-group bias in Experiments 1-3 was due to some intrinsic perceptual advantage for the local-team badge over the other badges (e.g., the badge of Oxford United was the only badge with yellow). Experiment 4 tested whether or not the enhanced performance on the local-team badge was related to the physical characteristics of the stimuli.

\section{Method}

Unless otherwise mentioned, the method was the same as that in Experiment 2. For this experiment, we did not take the dislike ratings.

Participants Sixteen university students, eight male, eight female (mean age $=25 \pm 4$ ), took part.

Results

The mean familiarity ratings were in-group $=3$, rival $=$ 3 , and neutral $=4$. These familiarity ratings were overall reduced for these participants as compared with the football fans; the ratings also did not differ across the teams, $F(2,30)=2.1, p<.135$.

$R T S$ For each participant, correct responses shorter than $150 \mathrm{~ms}$ or longer than $1,000 \mathrm{~ms}$ (corresponding to approximately $\pm 3 S D$ s from the mean) were excluded. This resulted in rejecting $1 \%$ of the entire data set. The analysis was performed on the remaining trials. A $2 \times 3$ ANOVA on the RTs showed a significant effect of match, $F(1,15)=34.80, p<.0001, \eta^{2}=.699$; participants were significantly faster on match than on mismatch trials $(p<001)$. The main effect of team was not significant, $F(2,30)=0.15, p>.861$, and neither 

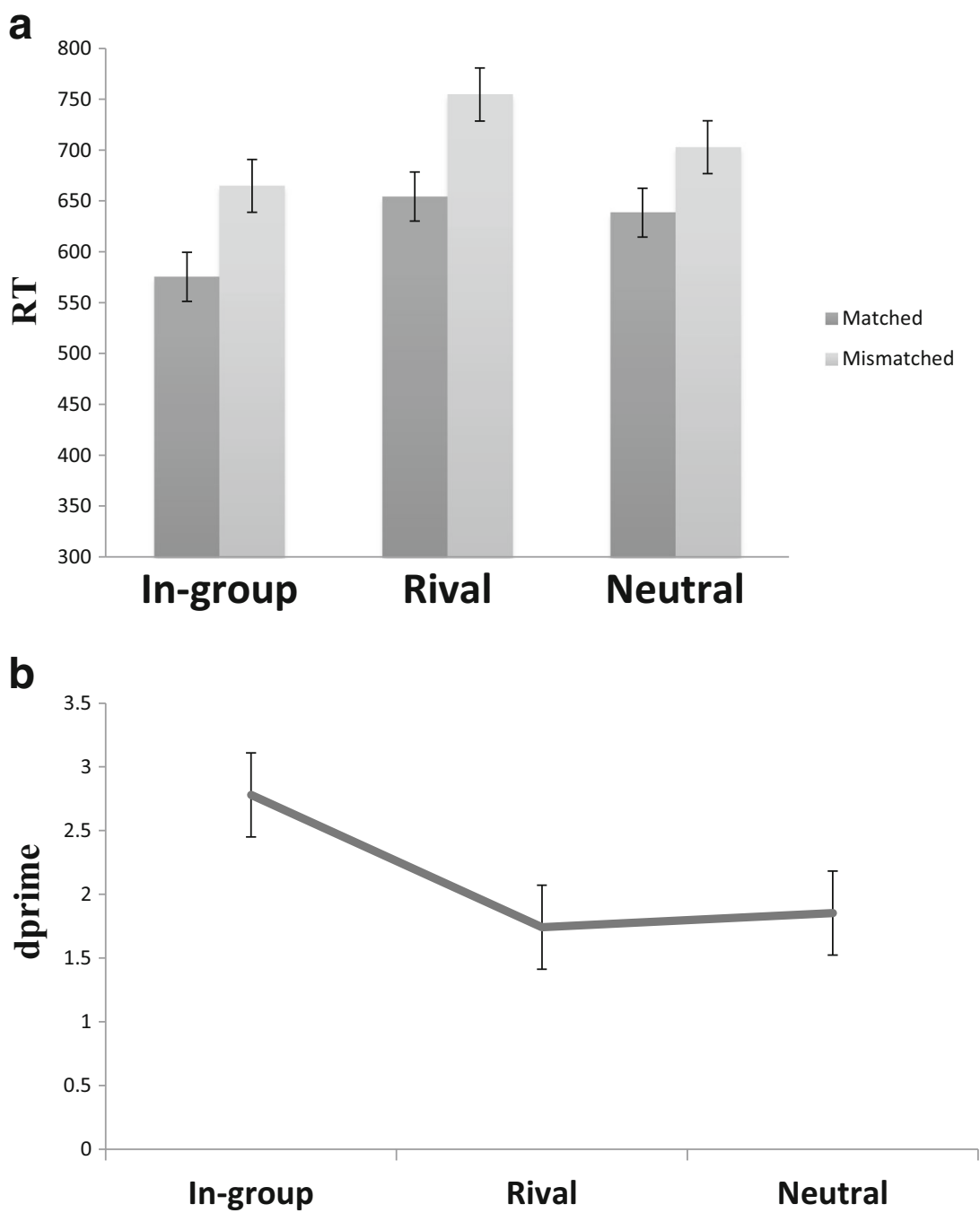

Fig. 5 (a) Mean correct RTs (in milliseconds) for match and mismatch trials in Experiments 3a (simultaneous presentations). (b) All $d$ prime values for each team in Experiment 3a.

was the interaction between match condition and team, $F(2,30)=2.73, p>.10 .^{5}$

$D$ prime and response criterion The analysis of the $d$ prime results did not yield any significant results, $F(2,30)=2.14, p$ $>.14$. The same held for the analyses of response criterion, $F(2,30)=1.02, p>.37$.

The mean RTs on match and mismatch trials, and the $d$ prime values for each team in Experiment 4, are shown in Figs. $8 \mathrm{a}$ and $\mathrm{b}$.

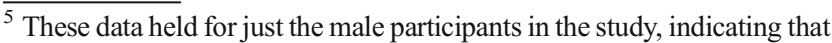
any differences between these data and those for the football supporters (Exps. 1-3) were not due to the involvement of more female participants in Experiment 4. Note, however, that the experiment aimed to test for effects of the stimulus per se (e.g., its color), even when it had no in-group association. It is highly unlikely that the effects of the stimulus (its color, shape) would differ between male and female participants.
}

The mean accuracy and RTs for the match and mismatch trials in Experiment 4 are presented in Table 6.

Discussion

No evidence emerged here of differences in a perceptualmatching task for individuals who were not football fans of the in-group team. We concluded that there were no intrinsic advantages for matching the Oxford United badge, as compared with the other badges.

\section{Experiment 5: testing effects of familiarity (control study 2)}

Experiment 5 was designed as a test of stimulus familiarity on matching performance. Here, instead of examining matches of football team badges to shapes, we examined performance 

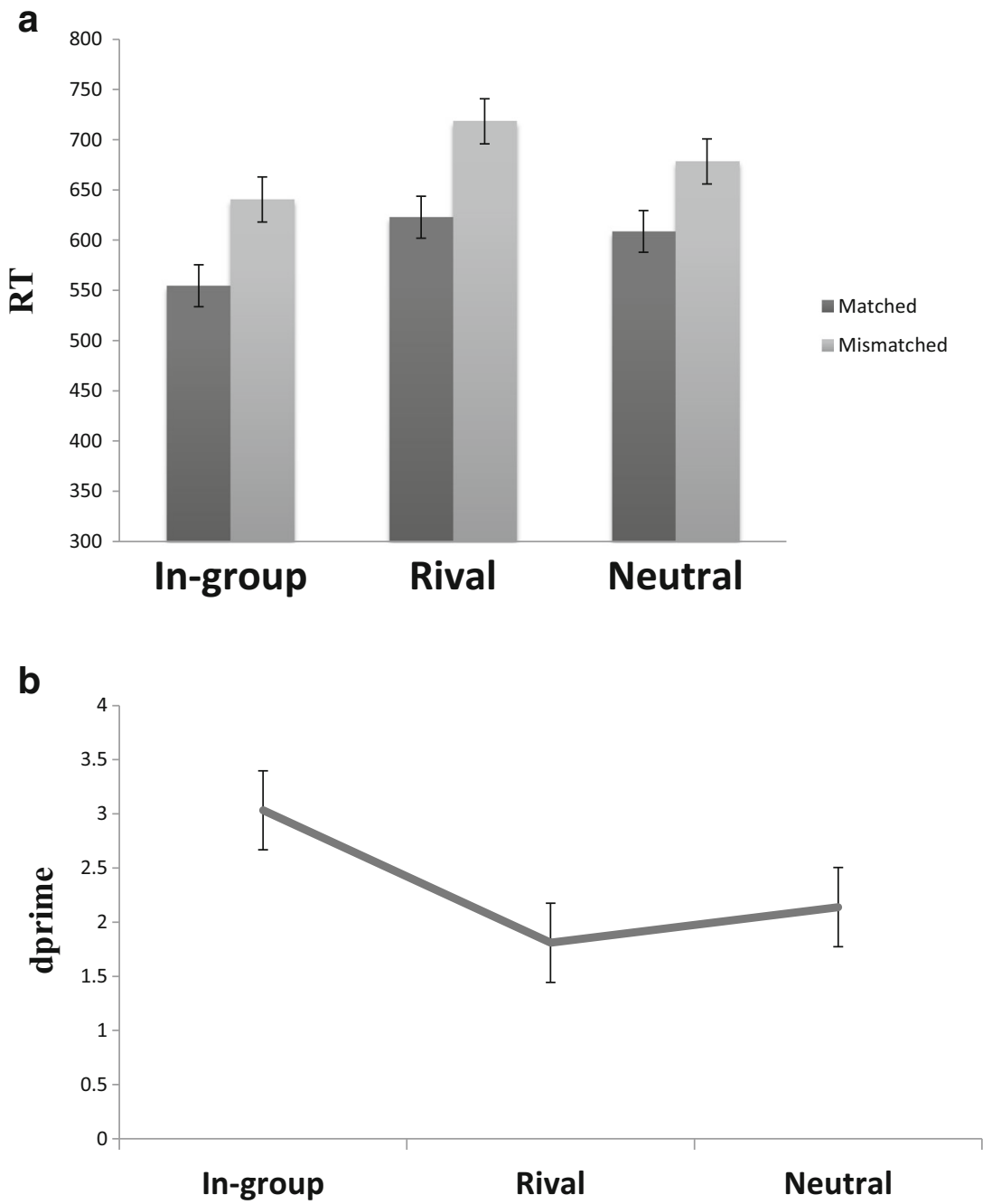

Fig. 6 (a) Mean correct RTs (in milliseconds) for match and mismatch trials in Experiments 3b (sequential presentations). (b) All $d$ prime values for each team in Experiment $3 b$.

when participants matched images of animals to the shapes, and we chose animals that varied in their familiarity to the participants. The animals selected varied more widely in familiarity than did the football teams for the football fans in Experiments 1-3. Following Experiment 1, we assessed performance when four associations were to be learned. One animal (the cow) received uniform familiarity ratings of 7

Table 4 Mean correct RTs (SDs in parentheses) and proportions of correct responses ( $S D$ s in parentheses) in Experiment 3a

\begin{tabular}{llll}
\hline Matching Condition & Group & RT & Accuracy \\
\hline Matched & In-group & $575(100)$ & $.95(.05)$ \\
& Rival & $654(116)$ & $.79(.10)$ \\
& Neutral & $638(114)$ & $.83(.09)$ \\
Mismatched & In-group & $664(118)$ & $.82(.07)$ \\
& Rival & $754(123)$ & $.78(.11)$ \\
& Neutral & $702(123)$ & $.76(.11)$ \\
\hline
\end{tabular}

( maximum familiarity); the others $($ donkey $=5.3$, camel $=$ 4.5 , and zebra $=4.7)$ received lower scores from an independent set of 30 raters. There were overall differences in familiarity between the stimuli $\left[F(3,87)=252.87, p<.0001, \eta^{2}=\right.$ .897], and the cow was rated as more familiar than the other stimuli, which did not differ $(p \mathrm{~s}<.001)$. If familiarity is critical, then there should be more efficient matching of the

Table 5 Mean correct RTs ( $S D$ s in parentheses) and proportions of correct responses ( $S D \mathrm{~s}$ in parentheses) in Experiment $3 \mathrm{~b}$

\begin{tabular}{llll}
\hline Matching Condition & Group & RT & Accuracy \\
\hline Matched & In-group & $554(108)$ & $.95(.04)$ \\
& Rival & $622(131)$ & $.79(.12)$ \\
& Neutral & $608(130)$ & $.83(.10)$ \\
Mismatched & In-group & $640(118)$ & $.86(.06)$ \\
& Rival & $718(133)$ & $.78(.12)$ \\
& Neutral & $678(137)$ & $.82(.14)$ \\
\hline
\end{tabular}



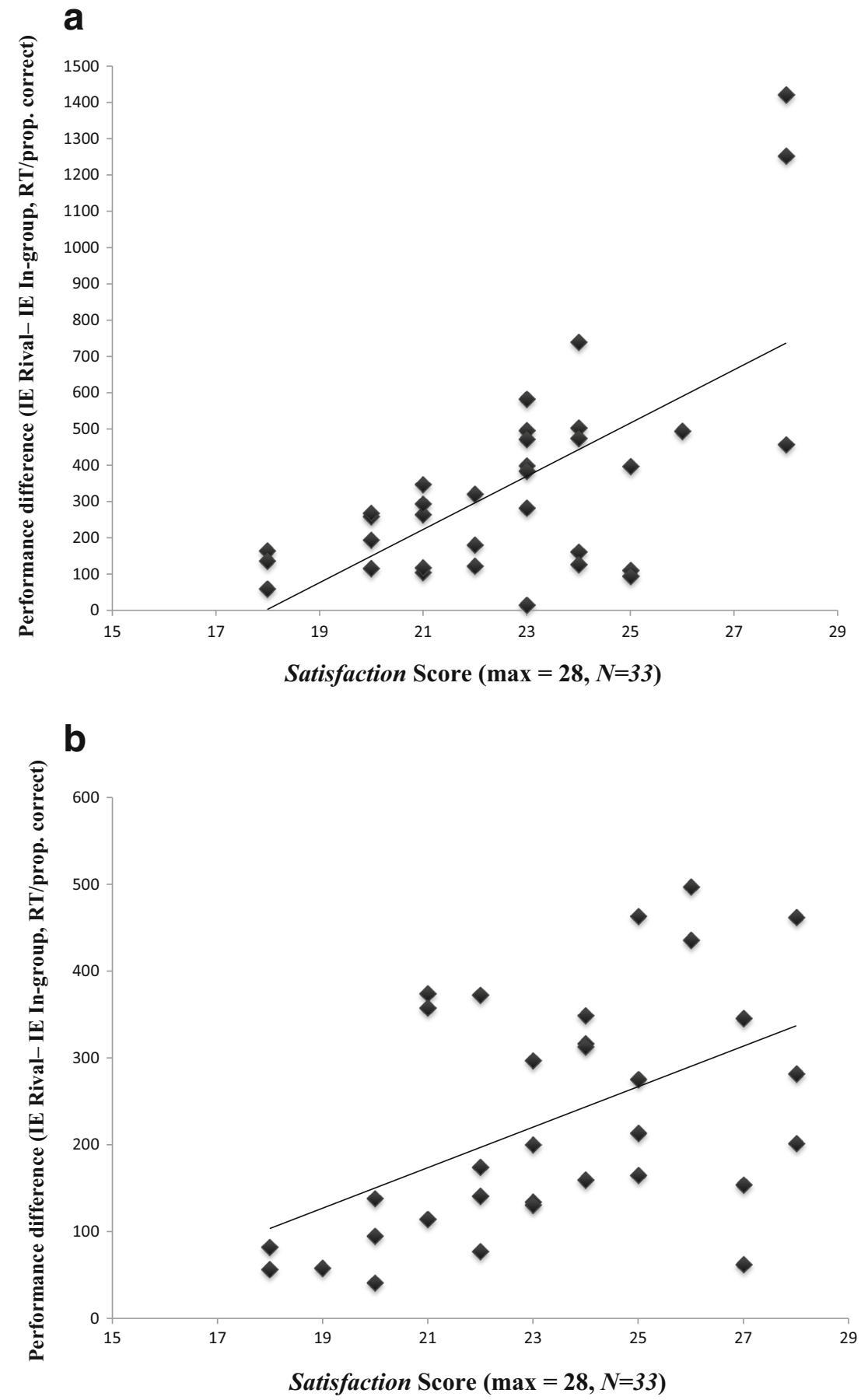

Fig. 7 Correlations between in-group satisfaction ratings and the matching advantage for in-group over rival teams, with (a) simultaneous presentations (Exps. 1 and 3a pooled) and (b) sequential presentations (Exps. 2 and $3 b$ pooled).

shapes to the cow than when the shapes were matched to the other animals.

\section{Method}

Unless otherwise mentioned, the method was the same as in Experiment 1.
Stimuli and procedure We used the same procedure as in Experiment 1, except that we replaced the football badges with same-size drawn images of animals taken from a standard database (Snodgrass \& Vanderwart, 1980). The animals were a cow (the most familiar animal), donkey, zebra, and camel (less familiar animals). The animals were all drawn in the same pose and viewed against a white background. 

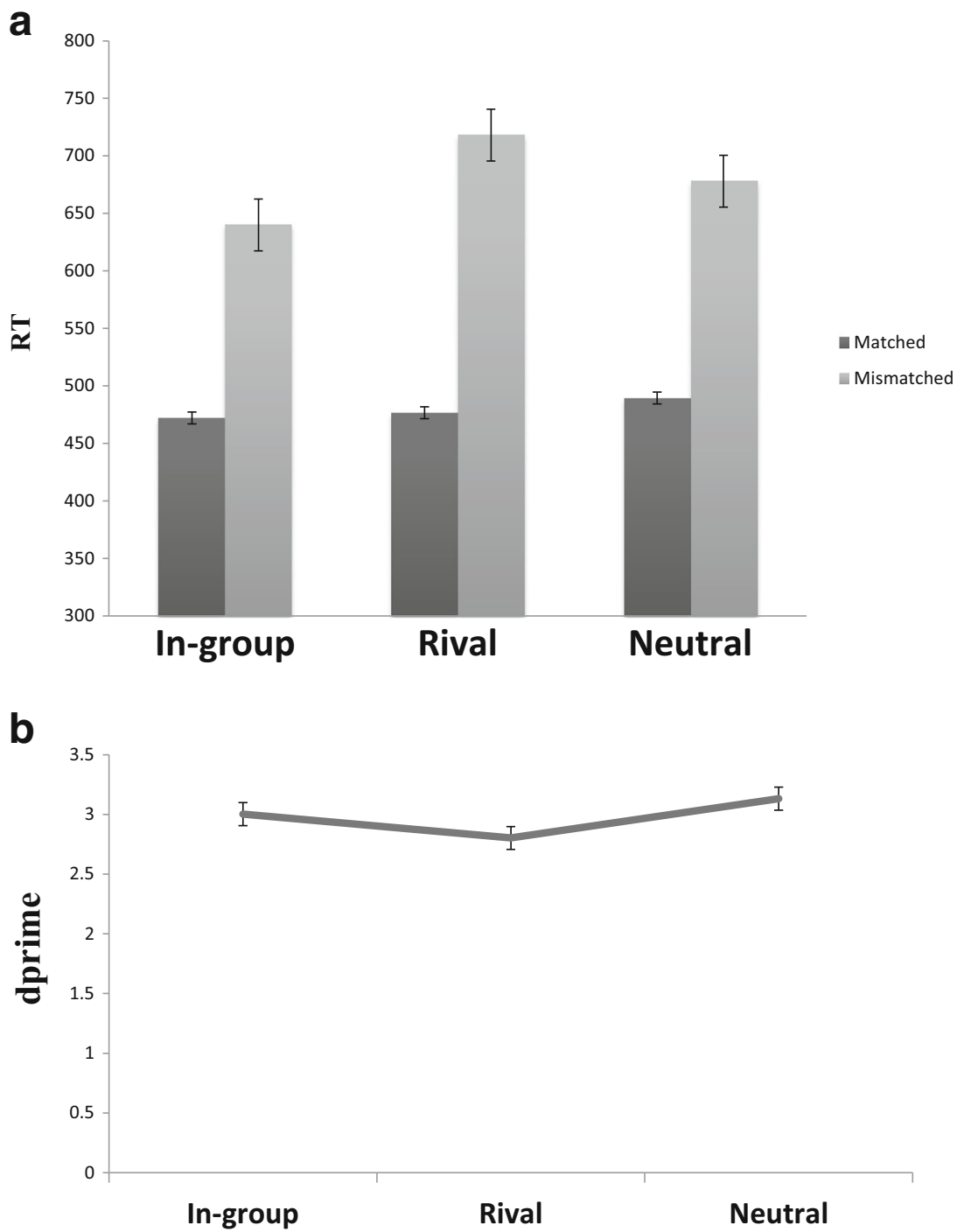

Fig. 8 (a) Mean correct RTs (in milliseconds) for match and mismatch trials in Experiment 4 (not football supporters). (b) All $d$ prime values for each team.

Participants Thirty university students, 23 female, seven male (mean age $=26 \pm 5$ years) took part.

\section{Results}

$R T s$ For each participant, correct responses shorter than $150 \mathrm{~ms}$ or longer than $1,000 \mathrm{~ms}$ were excluded. This resulted in rejecting $5 \%$ of the entire data set. The analysis was performed on the remaining trials. A $2 \times$ 4 ANOVA on the RTs showed a significant effect of match condition, $F(1,29)=192.59, p<.0001, \eta^{2}=$ .869 ; participants were significantly faster to respond to matching than to mismatching pairs. However, neither the main effect of animal, $F(3,87)=0.076, p<.973$, $\eta^{2}=.003$, nor the interaction, $F(3,87)=0.423, p<$ .737 , approached significance.
D prime and response criterion Analysis of $d$ prime values also revealed no significant effect of animal, $F(3,87)=$ $1.26, p<.293$. Analysis of the response criterion did

Table 6 Mean correct RTs ( $S D$ s in parentheses) and proportions of correct responses ( $S D$ s in parentheses) in Experiment 4

\begin{tabular}{llll}
\hline Matching Condition & Group & RT & Accuracy \\
\hline Matched & In-group & $472(62)$ & $.92(.05)$ \\
& Rival & $476(63)$ & $.90(.08)$ \\
& Neutral & $489(69)$ & $.91(.07)$ \\
Mismatched & In-group & $542(68)$ & $.92(.03)$ \\
& Rival & $545(68)$ & $.90(.06)$ \\
& Neutral & $524(83)$ & $.94(.03)$ \\
\hline
\end{tabular}



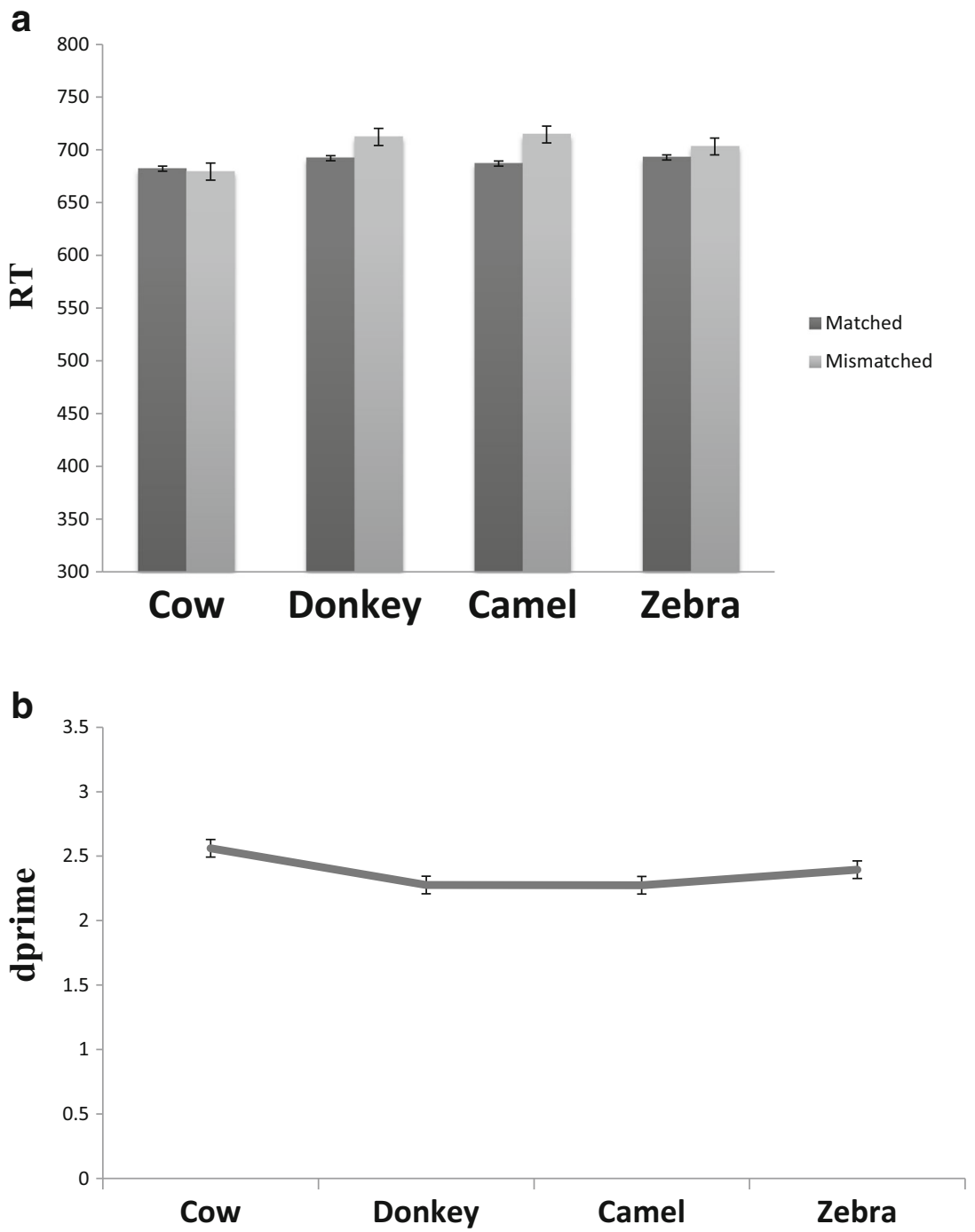

Fig. 9 (a) Mean correct RTs (in milliseconds) for match and mismatch trials in Experiment 5 (animal stimuli). (b) All $d$ prime values for each team.

show a significant effect of the animal, $F(3,87)=3.90$, $p<.012, \eta^{2}=.119$. Pairwise comparisons revealed that

Table 7 Mean correct RTs (SDs in parentheses) and proportions of correct responses ( $S D$ s in parentheses) in Experiment 5

\begin{tabular}{llll}
\hline Matching Condition & Group & RT & Accuracy \\
\hline Matched & Familiar (Cow) & $682(81)$ & $.87(.09)$ \\
& Unfamiliar 1 (Donkey) & $692(85)$ & $.87(.08)$ \\
& Unfamiliar 2 (Camel) & $687(85)$ & $.82(.14)$ \\
Mismatched & Unfamiliar 3 (Zebra) & $692(90)$ & $.85(.11)$ \\
& Familiar (Cow) & $766(74)$ & $.86(.09)$ \\
& Unfamiliar 1 (Donkey) & $762(65)$ & $.83(.09)$ \\
& Unfamiliar 2 (Camel) & $761(70)$ & $.86(.10)$ \\
& Unfamiliar 3 (Zebra) & $761(86)$ & $.86(.09)$ \\
\hline
\end{tabular}

the response criterion for the donkey was significantly different from that of the camel $(p<.003)$. The response criteria were not significantly different for the other animals.

The mean RTs on match and mismatch trials, and the $d$ prime values for each team in Experiment 5, are shown in Figs. $9 \mathrm{a}$ and $\mathrm{b}$.

The mean accuracy and RTs for the match and mismatch trials in Experiment 5 are presented in Table 7.

\section{Discussion}

We found no evidence here that stimuli that were more familiar were matched more efficiently than stimuli that were judged as being less familiar, even though the 
stimuli employed here varied more widely in rated familiarity than did the own- and rival-team badges in Experiments 1-3. The result provides support for the argument that stimulus familiarity was unlikely to be critical in generating the in-group advantage in the earlier experiments, adding to the argument from the sequential stimulus manipulation (Exps. 2 and $3 b$ ) that differences in the familiarity of the stimuli did not drive the in-group benefit.

\section{General discussion}

Across five sets of experiments, we examined whether ingroup associations established to neutral shapes could modulate perceptual matching with those shapes. After a short series of learning trials, in which participants associated a geometric shape with the badges of different teams, football fans showed a clear advantage for matches to their favorite team (their in-group), relative to matches to other (rival and neutral) teams. This effect occurred both on RTs and on a measure of perceptual sensitivity ( $d$ prime). It also occurred on both simultaneous match trials (Exps. 1 and $3 \mathrm{a}$ ) and sequential badge-shape trials (Exps. 2 and $3 b$ ).

The robustness of the in-group advantage across the presentation conditions indicates that the bias cannot simply be attributed to the visual familiarity of the in-group badge, since, under sequential conditions, responses were made to the shapes rather to pairs of badges and shapes appearing together. In addition, whereas a clear performance advantage was apparent for stimuli linked with the in-group team over both the rival and neutral teams, familiarity ratings showed a different pattern, and varied between the neutral team and the others (the in-group and rival teams, which did not differ). This last argument was also supported by the results from Experiment 5, in which we used stimuli that varied more widely in familiarity than did the football badges for our football supporters, and yet we failed to establish any effect of familiarity on matching performance. A further control study, Experiment 4, demonstrated that the in-group advantage did not reflect the intrinsic properties of the particular badges we used (e.g., the color of the Oxford United badge). Here we showed that individuals who were not football fans displayed no differences in matching the different badges used in Experiments 1-3. Rather than the familiarity and intrinsic properties of the stimuli being important, we argue that the enhanced responses to the in-group badge reflect the social value of the stimuli for the participants. This last argument is also supported by the correlations we performed, examining the relations between in-group biases and ratings of ingroup identification, with the in-group bias on matching being associated with ratings of in-group satisfaction.

Overall, these results indicate that in-group associations can be rapidly established and that they can affect the matching, and even the identification, of newly associated (and previously neutral) items (e.g., under sequential presentation conditions). The in-group preference here is consistent with the effects previously found in relation to the self by Sui et al. (2012). Indeed, one possible reason for a preference for in-groups over outgroups could be that people are more likely to find selfrelated attributes in their in-group (Allport, 1954/1979), perhaps reflecting some overlap between the cognitive representations of the self and of groups that we identify with strongly (Smith, Coats, \& Walling, 1999; Smith \& Henry, 1996). According to this account, people represent the in-group as part of the self. Linkage between cognitive representations for the self and the in-group might facilitate perceptual matching for ingroup stimuli.

An alternative proposal is that the better performance for in-group than for out-group stimuli can be attributed to emotional and motivational factors (Amodio, 2008). The emotional significance of a stimulus has been shown to modulate early perceptual processing (Schupp, Junghöfer, Weike, \& Hamm, 2003), and it may be that in-group pairs inherit a positive emotional tag, which in turn led to better matching performance here. Moreover, we found some evidence of a negative bias against the rival team in Experiments $3 \mathrm{a}$ and $3 \mathrm{~b}$, which might occur if these items inherit a negative emotional tag. Responses to stimuli with a positive emotional tag may be faster than those that have either no tag or a negative one.

In line with arguments about the emotional significance of the in-group, we found that the magnitude of the enhanced performance for the in-group varied as a function of the ratedsatisfaction component of the group identification questionnaire: The stronger the satisfaction with the ingroup, the more efficient the performance on the ingroup as opposed to the rival stimuli. The correlation results fit with the self-investment account of in-group identification (Leach et al., 2008). Self-investment is directly linked to the amount of commitment that one shows for group activity. For instance, individuals who identify strongly with their in-group are more likely to feel psychological and emotional bonds with their in- 
group (Lewin, 1948), and they may experience greater reward by acting in relation to the in-group.

Our data on newly established associations fit with other results from face perception, in which social categorization has been shown to produce rapid changes on performance to stimuli that do not have long-term links to the experimentally manipulated social groups (Van Bavel, Packer, \& Cunningham, 2011). In studies of face recognition, such effects are associated with changes in the configural processing of faces (Cassidy et al., 2011; Hugenberg, \& Sacco, 2008). The data indicate that group identification can enhance processing of the perceptual properties of newly associated stimuli.

Relative to the robust evidence for enhanced performance for in-group associations, the evidence for suppression of the rival team was weak, for both RT and sensitivity measures. This may be because in naturally established groups (football teams, for football fans), all out-groups are perceived as being homogeneous (Ostrom \& Sedikides, 1992). Notably, this was not due to the rival team being in some sense neutral. The football fans had strong negative opinions about the rival team, reflected in their ratings of disliking; even so, this did not lead to robust suppression of responses relative to stimuli associated with neutral teams. The data indicated that new associations can easily be formed to outas well as in-group stimuli, but the in-group associations uniquely produce enhancement of matching and identification performance for formerly neutral stimuli. This general effect of "in-group favoritism but not outgroup derogation" is supported by several social psychology studies. For instance, in the minimal-group paradigm, participants often allocate reward to their ingroup, but without necessarily punishing out-group members (see, e.g., Brewer, 1979, 1999; Goette, Huffman, \& Meier, 2006, for a review).

One other finding was that performance was affected by the context of the experiment. In general, participants performed better under sequential than under simultaneous presentation conditions (in Exps. 2 and $3 \mathrm{~b}$ vs. Exps. 1 and 3a), and the differences between the teams were smaller (though still highly reliable) with sequential presentations. This is not surprising, given that under sequential presentation conditions participants can generate an expectancy of the upcoming stimulus, and this then reduces the benefit for in-group items. Despite this, however, the in-group effect remained.

Alongside the changes in perceptual sensitivity, we found some changes in the response criterion adopted. In the main, participants adopted a less conservative criterion for responding to the in-group than to the other teams, though this was not always the case (Exp. 2). In addition, participants tended to be more conservative when responding to the rival team than to the neutral team (Exps. 1-3a). These shifts in response criterion exert effects that are independent of effects based on shifts in sensitivity (Macmillan, 1993), and indeed, we failed to find any correlations between the response criterion and $d$ prime measures. The effects on the response criterion may arise at a response rather than a perceptual stage of processing. Group biases may modulate not only our perceptual responses to stimuli, but also the threshold at which we are willing to respond to in-group- and rival-associated items. Our results contrast with those of some previous studies, in which it has been found that the response criterion can be lower for other-race than for own-race faces (Criss \& McClelland, 2006; Meissner \& Brigham, 2001). The contrasting results may be due to the level of familiarity of own-race faces, which makes participants adopt a stricter response criterion (especially when recognition is assessed). In our paradigm, however, we reduced the overall influence of familiarity, and here a stricter criterion for the in-group stimuli was not adopted.

The exact neural mechanisms responsible for the enhanced performance for in-group stimuli have not been fully understood yet. However, several lines of research, including neuroimaging studies, suggest that some parts of the so-called "social brain," including the amygdala (Anderson \& Phelps, 2001) and the medial part of prefrontal cortex (Sui, Rotshtein, \& Humphreys, 2013), might play a role in the enhanced processing of stimuli that are emotionally salient and related to the self. It will be helpful for future studies to explore the neural correlates of in-group bias in visual perception, to test the relations between in-group effects and those of emotion and self-interest. In addition, it will be important to examine whether the in-group biases that we have established can predict in- and out-group differences in attitude and other social behaviors. For example, if individuals perceive in-group-related stimuli more accurately and faster than out-group-related stimuli, then our sensitivity to variations and individuality within the out-group may be decreased. This line of research thus has important implications for broader areas of social behavior, including intergroup conflict and prejudice, and might pave the way to a better understanding of how we might be able to help resolve, or at least weaken, prejudice.

Author note This work was supported by grants from the Leverhulme Trust to the third and fourth authors, by ERC Advanced Investigator Award No. 323833 (PePe) to the fourth author, and by a grant from the National Science Foundation, China, to the second author. The work was conducted in partial fulfillment of a $\mathrm{PhD}$ by the first author. 


\section{Appendix}

Multicomponent In-group Identification questionnaire (Adapted based on Leach et al., 2008)

\section{I feel a bond with Oxford United supporters.}

Strongly agree Agree Agree somewhat Undecided Disagree somewhat Disagree Strongly disagree
7
6
5
4
3
2
1

\section{I feel solidarity with Oxford United supporters.}

Strongly agree Agree Agree somewhat Undecided Disagree somewhat Disagree Strongly disagree

$\begin{array}{lllllll}7 & 6 & 5 & 4 & 3 & 2 & 1\end{array}$

3. I feel committed to those who support Oxford United

Strongly agree Agree Agree somewhat Undecided Disagree somewhat Disagree Strongly disagree

$\begin{array}{lllllll}7 & 6 & 5 & 4 & 3 & 2 & 1\end{array}$

4. I am glad to be Oxford United supporter.

Strongly agree Agree Agree somewhat Undecided Disagree somewhat Disagree Strongly disagree

$\begin{array}{lllllll}7 & 6 & 5 & 4 & 3 & 2 & 1\end{array}$

5. I think that Oxford United supporters have a lot to be proud of.

Strongly agree Agree Agree somewhat Undecided Disagree somewhat

$6-5$

4

3

Disagree Strongly disagree

6. It is pleasant to be a fan of Oxford United.

Strongly agree Agree Agree somewhat Undecided Disagree somewhat 7

6

5

4

3

Disagree Strongly disagree

Being fan of Oxford United gives me a good feeling.

Strongly agree Agree Agree somewhat Undecided Disagree somewhat 7

6

5

4

3

Disagree Strongly disagree

8. I often think about the fact that I am a fan of Oxford United .

Strongly agree Agree Agree somewhat Undecided Disagree somewhat 7

5

4

3

Disagree Strongly disagree

9. The fact that I am a fan of Oxford United is an important part of my identity.

Strongly agree Agree Agree somewhat Undecided Disagree somewhat

Disagree Strongly disagree

7

6

5

4

3

2

1 
10. Being a fan of Oxford United is an important part of how I see myself.

Strongly agree Agree Agree somewhat Undecided Disagree somewhat Disagree Strongly disagree

7

6

5

4

3

2

1

11. I have a lot in common with the average Oxford United fan.

$\begin{array}{ccccccc}\text { Strongly agree } & \text { Agree } & \text { Agree somewhat } & \text { Undecided } & \text { Disagree somewhat } & \text { Disagree } & \text { Strongly disagree } \\ 7 & 6 & 5 & 4 & 3 & 2 & 1\end{array}$

\section{I am similar to the average Oxford United supporter.}

Strongly agree Agree Agree somewhat Undecided Disagree somewhat Disagree Strongly disagree

7

$\begin{array}{lll}6 & 5 & 4\end{array}$

2

1

13- People support Oxford United have a lot in common with each other.

Strongly agree Agree Agree somewhat Undecided Disagree somewhat

Disagree Strongly disagree

7

65

4

3

2

1

14- Oxford United fans are very similar to each other.

Strongly agree Agree Agree somewhat Undecided Disagree somewhat Disagree Strongly disagree

6

5

4

3

2

1

Is this a team supported by all or most of your family? Yes/no

How long have you been a supporter of your team? Years

About how many games by your team do you manage to actually watch every season?

How often do you watch the games by your team on TV?

Very often often fairly often moderately often sometimes rarely never

$\begin{array}{lllllll}7 & 6 & 5 & 4 & 3 & 2 & 1\end{array}$


Badge familiarity survey

Please state from 1 to 7 how familiar you are with the badges of these football clubs. Please also indicate whether each of the clubs can be serve as a rival (R) or neutral team $(\mathrm{N})$.

\begin{tabular}{|l|l|l|}
\hline & \\
\hline
\end{tabular}


Animal familiarity survey

Please state from 1 to 7 how familiar you are with each of the animals.

(1)

\section{References}

Allport, G. W. (1979). The nature of prejudice (25th anniv. ed.). Cambridge, MA: Perseus. (Original work published 1954)

Amodio, M. (2008). The social neuroscience of intergroup relations. European Review of Social Psychology, 19, 1-54.

Anderson, A. K., \& Phelps, E. A. (2001). Lesions of the human amygdala impair enhanced perception of emotionally significant events. Nature, 411, 305-309.

Brewer, M. B. (1979). In-group bias in the minimal intergroup situation: A cognitive-motivational analysis. Psychological Bulletin, 86, 307324. doi:10.1037/0033-2909.86.2.307

Brewer, M. B. (1999). The psychology of prejudice: In-group love or out-group hate? Journal of Social Issues, 55, 429-444.

Brigham, J. C., Bennett, L. B., Meissner, C. A., \& Mitchell, T. L. (2007). The influence of race on eyewitness memory. In R. Lindsay, D. Ross, J. Read, \& M. Toglia (Eds.), Handbook of eyewitness psychology: Memory for people (pp. 257-281). Mahwah, NJ: Erlbaum.
Brigham, J. C., \& Malpass, R. S. (1985). The role of experience and contact in the recognition of faces of own- and other-race persons. Journal of Social Issues, 41, 139-155.

Cassidy, K. D., Quinn, K., \& Humphreys, G. W. (2011). The influence of in-group/out-group categorization on same- and other-race face processing: The moderating role of inter- versus intra-racial context. Journal of Experimental Social Psychology, 47, 811-817.

Chelazzi, L., Miller, E. K., Duncan, J., \& Desimone, R. (1993). A neural basis for visual search in inferior temporal cortex. Nature, 363, 345347. doi:10.1038/363345a0

Criss, A. H., \& McClelland, J. L. (2006). Differentiating the differentiation models: A comparison of the retrieving effectively from memory model (REM) and the subjective likelihood model (SLiM). Journal of Memory and Language, 55, $447-460$.

Goette, L., Huffman, D., \& Meier, S. (2006). The impact of group membership on cooperation and norm enforcement: Evidence using random assignment to real social groups. American Economic Review, 96, 212-216. Retrieved from: http://www.jstor.org/stable/30034644

Green, D. M., \& Swets, J. A. (1966). Signal detection theory and psychophysics. New York, NY: Wiley. 
Greenwald, A., McGhee, D., \& Schwartz, J. (1998). Measuring individual differences in implicit cognition: The implicit association test. Journal of Personality and Social Psychology, 74, 1464-1480.

Hugenberg, K., \& Sacco, D. F. (2008). Social categorization and stereotyping: How social categorization biases person and perception in face memory. Social and Personality Psychology Compass, 2, 1052-1072.

Kastner, S., \& Ungerleider, L. G. (2000). Mechanisms of visual attention in the human cortex. Annual Review of Neuroscience, 23, 315-341. doi:10.1146/annurev.neuro.23.1.315

Leach, C. W., van Zomeren, M., Zebel, S., Vliek, M. L. W., Pennekamp, S. F., Doosje, B., \& Spears, R. (2008). Group-level self-definition and self-investment: A hierarchical (multicomponent) model of ingroup identification. Journal of Personality and Social Psychology, 95, 144-165. doi:10.1037/0022-3514.95.1.144

Lewin, K. (1948). Resolving social conflicts: Selected papers on group dynamics. New York, NY: Harper.

Macmillan, N. A. (1993). Signal detection theory as data analysis method and psychological decision model. In G. Keren \& C. Lewis (Eds.), $A$ handbook for data analysis in the behavioral sciences: Methodological issues (pp. 21-57). Hillsdale, NJ: Erlbaum.

Marr, D. (1982). Vision: A computational investigation into the human representation and processing of visual information. New York, NY: W. H. Freeman.

Mathur, V. A., Harada, T., Lipke, T., \& Chiao, J. Y. (2010). Neural basis of extraordinary empathy and altruistic motivation. NeuroImage, 51, 1468-1475. doi:10.1016/j.neuroimage.2010.03.025

Meissner, C. A., \& Brigham, J. C. (2001). Thirty years of investigating the own-race bias in memory for faces: A meta-analytic review. Psychology, Public Policy, and Law, 7, 3-35. doi:10.1037/10768971.7.1.3

Michel, C., Corneille, O., \& Rossion, B. (2007). Race categorization modulates holistic face encoding. Cognitive Science, 31, 911-924. doi: $10.1080 / 03640210701530805$

Michel, M., Corneille, O., \& Rossion, B. (2009). Holistic face encoding is modulated by perceived face race: Evidence form perceptual adaptation. Visual Cognition, 18, 434-455.

Molenberghs, P., Halász, V., Mattingley, J. B., Vanman, E. J., \& Cunnington, R. (2012). Seeing is believing: Neural mechanisms of action-perception are biased by team membership. Human Brain Mapping, 34, 2055-2068. doi:10.1002/hbm.22044

Murphy, K. R., Myors, B., \& Wolach, A. H. (2009). Statistical power analysis: A simple and general model for traditional and modern hypothesis tests. London, UK: Routledge.
Ostrom, T. M., \& Sedikides, C. (1992). Out-group homogeneity effects in natural and minimal groups. Psychological Bulletin, 112, 536-552. doi:10.1037/0033-2909.112.3.536

Röder, B., Kusmierek, A., Spence, C., \& Schicke, T. (2007). Developmental vision determines the reference frame for the multisensory control of action. Proceedings of the National Academy of Sciences, 104, 4753-4758. doi:10.1073/pnas.0607158104

Schupp, H. T., Junghöfer, M., Weike, A. I., \& Hamm, A. O. (2003). Emotional facilitation of sensory processing in the visual cortex. Psychological Science, 14, 7-13. doi:10.1097/00001756200306110-00002

Smith, E. R., Coats, S., \& Walling, D. (1999). Overlapping mental representations of self, in-group, and partner: Further response time evidence and a connectionist model. Personality and Social Psychology Bulletin, 25, 873-882.

Smith, E. R., \& Henry, S. (1996). An in-group becomes part of the self: Response time evidence. Personality and Social Psychology Bulletin, 22, 645-642. doi:10.1177/0146167296226008

Snodgrass, J. G., \& Vanderwart, M. (1980). A standardized set of 260 pictures: Norms for name agreement, image agreement, familiarity and visual complexity. Journal of Experimental Psychology: Human Learning and Memory, 6, 174-215. doi:10.1037/02787393.6.2.174

Spratling, M. (2008). Predictive coding as a model of biased competition in visual attention. Vision Research, 48, 1391-1408.

Sui, J., He, X., \& Humphreys, G. W. (2012). Perceptual effects of social salience: Evidence from self-prioritization effects on perceptual matching. Journal of Experimental Psychology. Human Perception and Performance, 38, 1105-1117. doi:10.1037/ a0029792

Sui, J., Rotshtein, P., \& Humphreys, G. W. (2013). Coupling social attention to the self forms a network for personal significance. Proceedings of the National Academy of Sciences, 110, 76077612. doi:10.1073/pnas.1221862110

Tajfel, H. (1982). Social psychology of intergroup relations. Annual Review of Psychology, 33, 1-39.

Townsend, J. T., \& Ashby, F. G. (1983). Stochastic modelling of elementary psychological processes. New York, NY: Cambridge University Press.

Van Bavel, J. J., Packer, D. J., \& Cunningham, W. A. (2011). Modulation of the fusiform face area following minimal exposure to motivationally relevant faces: Evidence of in-group enhancement (not outgroup disregard). Journal of Cognitive Neuroscience, 23, 33433354. doi:10.1162/jocn a 00016 